\title{
Falta grave e sua interferência na rotatividade dos presídios do Estado de São Paulo: uma análise a partir das decisões do DEECRIM - $2^{\mathrm{a}} \mathrm{RAJ}$
}

\author{
Gross negligence and its interference with the \\ state of São Paulo prisons turnovers: an analysis \\ stemmed from DEECRIM - $2^{a} R A J$ sentences
}

\section{Bruno Barros Mendes ${ }^{1}$}

Pontifícia Universidade Católica de Minas Gerais, Belo Horizonte, MG, Brasil brunobarrosmendes@gmail.com http://lattes.cnpq.br/2126627442926661

Dttp://orcid.org/0000-0002-2820-2195

Resumo: O presente artigo tem como objetivo compreender o que é disciplina no âmbito do sistema penitenciário brasileiro, o que são as faltas disciplinares nos termos da Lei de Execuções Penais, como são classificadas e quais suas consequências durante o processo executório. Além disso, apresenta pesquisa empírica consistente em análise dos procedimentos julgados pelo Departamento Estadual de Execução Criminal da $2^{\mathrm{a}}$ Região Administrativa Judiciária (DEECRIM-2 ${ }^{\mathrm{a}} \mathrm{RAJ}$ ), submetidos ao Tribunal de Justiça do Estado de São Paulo, tendo como principal objetivo verificar se os procedimentos disciplinares violam direitos e garantias fundamentais dos sentenciados na prática. Por meio de acesso ao portal eletrônico do Tribunal Paulista, foi possível realizar a seleção procedimentos analisados e comprovar o descompasso entre o procedimento previsto na lei com a prática real. Por fim, comparando os resultados com os relatórios oficiais emitidos pelo Departamento Penitenciário Nacional, aponta a possibilidade desse distanciamento

1 Especialista em Ciências Criminais pela Pontifícia Universidade Católica de Minas Gerais - PUC/Minas. Membro do Grupo de Pesquisa de Jurisprudência de Direitos Fundamentais da Unitoledo Araçatuba. Advogado. 
entre vigência e a efetividade dos direitos fundamentais estar interferindo na rotatividade dos presídios locais.

Palavras-Chave: Falta Grave; Execução Penal; Rotatividade; Garantias; Pesquisa Empírica; Araçatuba.

AвSTRACT: This paper aims to explain what disciplinary action in the Brazilian prison system is, as well as what violations of rules and infractions are in terms of the Law of Penal Actions, how they are classified and their consequences during the execution of the conviction decisions. Furthermore, this paper presents a consistent empirical research in the analysis of proceedings judged by the State Criminal Division of the 2nd Circuit Court (DEECRIM-2 $\left.{ }^{a} R A J\right)$, referred to the Court of Justice of the State of São Paulo, aiming to denote that the disciplinary actions (in administrative and judicial proceedings) violate prisoners human rights and fundamental guarantees. Through access to the Court of Justice of the State of São Paulo electronic portal, it was possible to select the analyzed proceedings here presented and demonstrate the mismatch between the procedures provided in law and the applied practice in the prisons. In conclusion, comparing the results obtained in the research with the official reports issued by the National Prison Department, the outcome is that, this critical distance between the force and the effectiveness of the human rights and fundamental guarantees, characterized by the Judicial Power aloofness concerning the prison population, interferes with the local prisons turnovers.

KeYwords: Gross Negligence; Penal Action; Turnovers; Guarantees; Araçatuba; Empirical Research.

SUMÁRIo: Introdução; 1. Procedimentos disciplinares; 2. Faltas disciplinares e suas consequências na execução da pena 3. A metodologia e o resultado das pesquisas; Considerações Finais; Referências.

\section{INTRODUÇÃO}

Sabemos que a disciplina não é algo próprio do sistema penitenciário, pelo contrário, faz parte da vida do homem. Em qualquer relação social, ela se aplica no sentido de se desenvolver tarefas e conviver de 
forma harmoniosa nos mais variados ambientes. Ela é, portanto, própria da vida em sociedade ${ }^{2}$.

Tratando-se a disciplina de elemento essencial da vida social, o instituto "deveres do preso" foi inserido no artigo 37 da Lei de Execuções Penais (LEP), visando à readaptação social e a manutenção da ordem no interior dos presídios, conforme item 63 da Exposição de Motivos 213, de 09 de maio de $1984^{3}$.

Em síntese, a disciplina no sistema prisional estabelece "um conjunto de normas observadas pelo recluso e estabelecidas pelo estatuto da unidade carcerária"4. Sua função é possibilitar a execução das regras de convívio e sua concretização se dá pela adesão às normas definidas pela Diretoria do Presídio, que envolvem obediência à hierarquia, sanções normalizadoras e procedimentos específicos de segurança ${ }^{5}$.

Não é necessário muito esforço para perceber que o sistema disciplinar teve sua finalidade deturpada, tornando-se instrumento de controle e sedimentação de injustiças no cárcere. Atualmente, apesar dos

2 FILHO, Luiz Carlos Gonçalves. A lei de execução penal e os efeitos decorrentes da prática de falta disciplinar de natureza grave. Dissertação (Mestrado em Direito) - Pontifícia Universidade Católica de São Paulo (PUC/SP), São Paulo, 2006, p.77.

3 “A instituição dos deveres gerais do preso (artigo 37) e do conjunto de regras inerentes à boa convivência (artigo 38), representa uma tomada de posição da lei em face do fenômeno da prisionalização, visando a depurá-lo, tanto quanto possível, das distorções e dos estigmas que encerra. Sem característica infamante ou aflitiva, os deveres do condenado se inserem no repertório normal das obrigações do apenado com ônus naturais da existência comunitária" (BRASIL, 1984).

4 FILHO, Luiz Carlos Gonçalves. A lei de execução penal e os efeitos decorrentes da prática de falta disciplinar de natureza grave. Dissertação (Mestrado em Direito) - Pontifícia Universidade Católica de São Paulo, São Paulo, 2006, p.78.

5 "O regime disciplinar prisional tem uma série de especificidades no que diz respeito ao conteúdo das proibições - e da própria ideia de ética e disciplina que as proibições veiculam, ao modo como as infrações são atribuídas e processadas, às possibilidades de defesa técnica e, ainda, às formas de articulação entre a administração pública e o poder judiciário” (MACHADO, Maira Rocha; PINTO, Patrícia Bocardo Batista. A punição na punição na punição: as múltiplas sanções aplicadas em caso de falta grave nas decisões do TJSP. Revista Brasileira de Ciências Criminais. vol. 152, n. 27. p. 117-143, fevereiro 2019). 
direitos dos presos serem diariamente violados pelo Estado, sem que exista qualquer consequência legal a favor dos detentos, o descumprimento dos deveres impostos aos reclusos é rigorosamente punido pelas autoridades administrativas e judiciais ${ }^{6}$.

Neste cenário, os conflitos entre presos e agentes penitenciários tornaram-se algo rotineiro, por um lado à população carcerária exigindo direitos básicos como alimentação, saúde, higiene e respeito aos visitantes ${ }^{7}$. Do outro, os servidores exigindo ordem e disciplina. Não é uma tarefa fácil manter a disciplina em presídios, por isso há um respaldo da legislação no sentido de penalizar as faltas disciplinares.

Diante da inobservância das regras de convivência, assim como da prática de algumas condutas previstas em lei, os sentenciados incorrem nas chamadas faltas disciplinares, que, de acordo com a gravidade do ato praticado, poderão ser classificadas como faltas graves, médias e leves.

No entanto, para que haja a classificação e imposição das respectivas sanções, a legislação estabelece uma sequência de atos administrativos e judiciais, que aqui serão denominados de procedimentos disciplinares, objeto central do presente estudo.

Levanta-se aqui a problemática. Será que os procedimentos disciplinares, administrativos e judiciais, responsáveis por julgar e classificar os atos faltosos praticados nos presídios paulistas, respeitam princípios constitucionais como acesso à justiça e o devido processo legal com exatidão?

Sendo assim, o trabalho deixa de lado as alegações ligadas à má administração penitenciária, questionando questões intimamente ligadas

6 "A resposta é bastante óbvia: a política criminal brasileira não possui a mínima preocupação em desenvolver o sistema prisional, em respeitar os direitos mais fundamentais do preso". (SCHIMIDT, Andrei Zenkner. Direitos, Deveres e Disciplina na Execução Penal. In: CARVALHO, Salo de (Org.). Crítica à Execução Penal. $2^{\circ}$ ed. Rio de Janeiro: Lumen. Juris, 2007, p. 235).

7 "A atual situação carcerária brasileira dispensa-nos de demonstrar que os direitos arrolados no art. $6^{\circ}$, na grande maioria dos casos, são simplesmente ignorados positivamente pelo Estado. Aliás, a satisfação de direitos sociais na execução da pena atravessa uma crise bem mais acentuada em relação ao desrespeito dos direitos individuais nessa mesma matéria." (SCHIMIDT, Andrei Zenkner. Direitos, Deveres e Disciplina na Execução Penal. In: CARVALHO, Salo de (Org.). Crítica à Execução Penal. $2^{\circ}$ ed. Rio de Janeiro: Lumen. Juris, 2007, p. 233). 
ao sistema de justiça, a estrutura do processo de execução penal e aos vícios práticos decorrentes dos inúmeros problemas normativos, o que talvez constitua o epicentro da crise penitenciária no Brasil ${ }^{8}$.

Inicialmente, por meio de revisão bibliográfica e legislativa, o presente artigo tem como objetivo compreender o que é disciplina e como ela funciona durante a execução da pena, o que são as faltas disciplinares, como são classificadas e quais suas consequências durante o processo executório, buscando a compreensão teórica sobre esse peculiar sistema disciplinar.

Após a abordagem teórica, o artigo apresenta pesquisa empírica consistente na análise de 56 procedimentos disciplinares julgados Tribunal de Justiça, advindos de recursos interpostos contra as decisões do Departamento Estadual de Execução Criminal da $2^{\text {a }}$ Região Administrativa Judiciária (DEECRIM-2 ${ }^{\mathrm{a} R A J}$ ), com o objetivo de verificar se os procedimentos analisados violam ou não direitos fundamentais dos acusados. Para tanto, foi necessário a utilização do portal eletrônico do mencionado Tribunal, onde foi possível realizar a seleção dos acórdãos e ter acesso aos procedimentos disciplinares através dos documentos anexados aos recursos. Verificou-se, ao final da pesquisa, que os procedimentos analisados, tanto no âmbito administrativo quanto na esfera judicial, violam direitos básicos como acesso à justiça e o devido processo legal.

Por fim, comparando os resultados obtidos com os dados oficiais do Departamento Penitenciário Nacional, levanta-se a possibilidade dessa constante violação de direitos, somada ao número de procedimentos instaurados e de sentenciados envolvidos nas sindicâncias, estarem interferindo na rotatividade do sistema penitenciário Paulista, onde a maior parte dos sentenciados encontra-se em regime fechado.

8 Reforçando a posição de Salo de Carvalho ao afirmar que "mesmo se a Lei de Execução Penal fosse cumprida em sua integralidade os direitos dos apenados não estariam garantidos em decorrência da estrutura processual inquisitória que molda o último estágio do processo penal". (CARVALHO, Salo de. Da necessidade de Efetivação do Sistema Acusatório no Processo de execução Penal. Crítica à Execução Penal. $3^{\circ}$ ed. Rio de Janeiro: Lumen Juris, 2007, p. 419). 


\section{PROCEDIMENTOS DISCIPLINARES}

Como salienta Ada Pellegrini Grinover "a execução penal é uma atividade complexa de cunho administrativo e jurisdicional". Portanto, conforme regulamentado no art. 59 da Lei de Execuções Penais, diante da prática de ato indisciplinado, deverá ser instaurado procedimento interno na unidade prisional para sua apuração, observando o regulamento local, assegurando, em todos os casos, o direito de defesa. Após o termino da fase administrativa, a sindicância deverá ser submetida à esfera judicial ${ }^{10}$.

Da leitura do referido artigo, extrai-se que os procedimentos disciplinares podem ser considerados bifásicos, em um primeiro momento os atos serão analisados pela administração carcerária de acordo com a regulamentação local, só então, após o término do procedimento administrativo, a sindicância será submetida ao juiz competente, para que após a manifestação das partes, atribua ou não consequências jurídicas ao fato.

No âmbito da Administração Penitenciária Paulista, as sindicâncias estão regulamentadas pelos artigos 58 a 75 da Resolução 144 de 2010, da Secretaria da Administração Penitenciária do Estado de São Paulo ${ }^{11}$.

9 GRINOVER, Ada Pellegrini. Processo de execução e direito de defesa. Revista de informação legislativa, Brasília, v. 59, n. 15, p. 56, 1978.

10 "Não mais simples detentor de obrigações, deveres e ônus, o réu torna-se titular de direitos, faculdades e poderes. E como em todo e qualquer processo, que não seja mera ordenação de atos, mas que seja entendido em sua função garantidora, ficam asseguradas ao réu as garantias constitucional do "devido processo legal"; o direito de defesa (compreendendo a defesa técnica), o contraditório, o duplo grau de jurisdição, a publicidade e, evidentemente, a igualdade processual. (GRINOVER, Ada Pellegrini. Processo de execução e direito de defesa. Revista de informação legislativa, Brasília, v. 59, n. 15, p. 56, 1978).

11 "Se os processos de execução penal ou de apelação se desenrolam fundamentalmente no âmbito do sistema de justiça; na sindicância, funcionários e gestores da prisão desempenham um maior protagonismo. Mesmo sua formatação institucional, sua estrutura jurídica, é híbrida: parte estabelecida pela Lei de Execuções Penais (LEP) - Lei 7.2010/84; parte a cargo de autoridades administrativas da esfera estadual - em São Paulo, a última regulamentação se deu através da Resolução SAP 144, de 29 de junho de 2010.” (GODOI, Rafael. Fluxos em cadeia: as prisões em São Paulo na vidada dos tempos. Tese (Doutorado em Sociologia) - Departamento de Sociologia, FFLCH, USP, São Paulo, 2015, p.98). 
Tomando como análise a referida resolução, inicialmente, quando um servidor presencia ou tem conhecimento da ocorrência de uma suposta falta disciplinar de qualquer natureza por parte de algum preso, deve ser imediatamente elaborado "Comunicado de Evento" e encaminhado ao diretor da unidade prisional, discriminando minuciosamente a data, hora, local, identificação do (s) preso (s) envolvido (s), circunstâncias do fato e testemunhas.

Após a comunicação, cabe ao diretor adotar medidas cautelares que entender necessárias e instaurar, através de portaria, o procedimento disciplinar em até 5 dias a partir da data do conhecimento do fato, o qual deverá ser concluso em até 30 dias. No entanto, na prática, o presente prazo não conduz a invalidação do procedimento e da punição, deixando os sentenciados à deriva da morosidade estatal, constituindo, nas lições de Rodrigo Duque Estada, um "atentado contra a celeridade na execução penal" 12 .

O artigo 64 e seu $\S 1^{\circ}$ da Resolução 144 de 2010 (São Paulo), regulamenta o procedimento em si, nos seguintes termos:

Artigo 64 - Após a instalação dos trabalhos, a autoridade apuradora deve providenciar o que segue: I- data, hora e local da audiência; II- citação pessoal do preso acerca da acusação, cientificando-o sobre o comparecimento à audiência na data e hora designadas, acompanhado de advogado; III- intimação das testemunhas da administração.\$1 $1^{\circ}$ na impossibilidade de citação do preso em face de fuga ou abandono, deve a autoridade apuradora solicitar ao diretor da unidade prisional o sobrestamento do procedimento até a recaptura, informando a autoridade judicial competente para eventual decisão cautelar. $\$ 2^{\circ}$ - a autoridade apuradora, no momento da citação do preso, deve inquiri-lo sobre a existência de defensor constituído para proceder a sua defesa, cientificando-o sobre a possibilidade de ser assistido por defensor dativo.

Após a instauração e a citação de todos os envolvidos, o procedimento administrativo segue rito o sumaríssimo, com audiência única, facultando ao acusado a apresentação de defesa preliminar, podendo

12 ROIG, Rodrigo Duque Estrada. Execução Penal: teoria crítica. 2 ed. São Paulo: Saraiva, 2016. 
apresentar neste momento até 03 (três) testemunhas, assim como requerer e produzir outras provas, sendo facultado a autoridade limitar ou excluir as provas excessivas, impertinentes ou protelatórias. Diante da impossibilidade de produção de provas em uma única audiência, poderá ser designado outros atos. Apesar da previsão legal, a jurisprudência classifica tal procedimento como "informal"13, o que contribui com a violação sistêmica de direitos no âmbito administrativo, como ficará demonstrado na pesquisa.

Encerradas as fases de instrução e defesa, a autoridade apuradora apresenta o relatório geral, encaminhando os autos ao diretor da unidade prisional, que proferirá a decisão final. Após a conclusão, o procedimento administrativo deve ser imediatamente enviado para o juízo competente, que, por sua vez, deveria fiscalizar as regularidades do procedimento administrativo e garantir o contraditório e a ampla defesa, também na esfera judicial ${ }^{14}$.

No âmbito judicial, os artigos 194 a 197 da Lei de Execuções Penais discorrem sobre os procedimentos em geral que se desenvolve nas Varas de Execuções Penais. Na prática, quando o assunto envolve faltas disciplinares, após o procedimento administrativo ser juntado aos autos, o Ministério Público, que deve assumir polo ativo da relação jurídica, é imediatamente intimado para se manifestar sobre o ato indisciplinado ${ }^{15}$.

13 "O rito sumaríssimo do processamento de faltas graves, considerado informal e célere pela jurisprudência, impõe prazos menores para a produção de provas e menor número de testemunhas (três)" (PINTO, Patírcia Bocardo Batista. Faltas disciplinares em penitenciárias femininas: um estudo das decisões do TJSP. Dissertação (Mestrado em Direito) - Fundação Getúlio Vargas, Escola de Direito de São Paulo, São Paulo, 2019, p. 64).

14 Sobre a importância da execução penal jurisdicionalizada: "a consolidação de uma execução penal jurisdicionalizada, mais humana, responsável e alinhada com o Estado de Direito, com viés abertamente voltado à finalidade de prevenção especial positiva e a harmônica integração social do condenado e do internado, como preconiza seu artigo inaugural" (PAVARINI, Massimo; GIAMBERARDINO, André. Teoria da pena e execução penal. Uma introdução crítica. Rio de Janeiro: Lumem Juris, 2011, p. 227).

15 "Para aproximarmos a execução penal da estrutura dialética do processo de conhecimento (ideal garantista), devemos estabelecer de forma clara qual é a esfera de atuação de cada agente. É imprescindível que o Ministério Público assuma a iniciativa da execução e também atue no polo ativo ao seu longo" (LOPES JR, Aury. Revisando o Processo de Execução Penal a partir 
Após a manifestação do parquet, o sentenciado, devidamente representado, deve ser ouvido. No entanto, no cotidiano forense, a oitiva do sentenciado é substituída pela manifestação escrita da Defesa. A lei ainda ressalta que havendo necessidade de realização de provas pericial ou oral, o juiz aguardará a produção ou designará audiência.

Portanto, observando o texto legal é indiscutível a necessidade de garantir direitos relacionados ao devido processo legal, devendo o magistrado comportar-se como expectador da atividade das partes ${ }^{16}$, guiando-se pelos princípios da imparcialidade e respeitando outras atribuições indispensáveis ao juiz natural ${ }^{17}$.

Por fim, após a produção das provas e manifestação das partes, a autoridade judicial poderá absolver, anular, determinar diligências ou condenar o sentenciado pela prática de falta leve, média ou grave, sempre de forma fundamentada e individualizada ${ }^{18}$, vez que as faltas disciplinares

da Instrumentalidade Garantista. In: CARVALHO, Salo de (Org.). Crítica à Execução Penal. $2^{\circ}$ ed. Rio de Janeiro: Lumen. Juris, 2007, p. 381.)

16 "O processo de execução penal (e o de conhecimento também) exige um juiz de garantias e não um juiz inquisidor. A posição desse juiz na execução é muito similar aquele que deve adotar na investigação preliminar, conforme já apontamos em outra oportunidade. O juiz garante não investiga e tampouco assume uma posição de inquisidor, ativo na busca de elementos, pois isso acarreta um claríssimo comprometimento da imparcialidade (nisso reside os equívocos do nosso sistema)." (LOPES JR, Aury. Revisando o Processo de Execução Penal a partir da Instrumentalidade Garantista. In: CARVALHO, Salo de (Org.). Crítica à Execução Penal. $2^{\circ}$ ed. Rio de Janeiro: Lumen. Juris, 2007, p. 381).

17 Sobre a importância do juiz natural na execução da pena, Claudio Prado Amaral: "sua principal função consiste em inviabilizar a interferência de outros Poderes do Estado, especialmente o Executivo, no exercício da atividade jurisdicional. Se trata, pois, de uma garantia tão importante quanto a própria jurisdição. É uma garantia do cidadão. Na medida em que a Execução interfere no tempo de encarceramento de modo decisivo, apenas utilizando a "máquina", fere-se substancialmente a garantia do juiz natural". (AMARAL, Claudio do Prado. Em busca do devido processo de execução penal. Revista Brasileira de Ciências Criminais, São Paulo, ed. RT, n. 81, ano 17, p. 178, 2007).

"Tais regras básicas de um modelo garantista devem ser aplicadas na sua totalidade no processo de execução, inclusive na apuração de faltas disciplinares, pois muitas vezes a sanção é tão ou mais grave que aquele atribuída pela lei penal a condutas delituosas". (LOPES JR, Aury. Revisando o Processo de Execução Penal a partir da Instrumentalidade Garantista. In: CARVALHO, Salo de (Org.). Crítica à Execução Penal. $2^{\circ}$ ed. Rio de Janeiro: Lumen. Juris, 2007, p. 381). 
implicam em consequências gravíssimas, que interferem diretamente na liberdade de locomoção dos sentenciados ${ }^{19}$.

\section{FALTAS DISCIPLINARES E SUAS CONSEQUÊNCIAS NA EXECUÇÃO DA PENA}

A própria Lei de Execuções Penais (LEP), em seu art. 49, classifica as faltas disciplinares em leves, médias e graves, dando autonomia para que as leves e as médias sejam definidas pela localidade, ou seja, para que tenham apenas consequências administrativas, que poderão ser aplicadas, nos termos da lei, pelo próprio diretor da unidade prisional ${ }^{20}$.

Art. 49. As faltas disciplinares classificam-se em leves, médias e graves. A legislação local especificará as leves e médias, bem assim as respectivas sanções. Parágrafo único. Pune-se a tentativa com a sanção correspondente à falta consumada.

Já as faltas graves - objeto da presente pesquisa - são definidas nos artigos 50 a 52 da LEP, nos quais também estão previstas algumas consequências. No art. 50 da LEP são previstas as seguintes condutas para os condenados à pena privativa de liberdade ou ao preso provisório naquilo que lhes couber: incitar ou participar de movimento para subverter

19 "Observa-se, portanto, que até mesmo em atividades cuja intervenção judicial é obrigatória por lei, como no caso dos direitos relacionados ao sistema progressivo de cumprimento da pena, não se pode assegurar que a jurisdição exerça o seu papel declarado de garantia dos direitos. Pelo contrário, nesta seara, a intervenção judicial parece exercer uma função oposta ao que dela se espera, posto que na realidade concreta a atividade judicial tem sido muito mais um mecanismo de violação do que de garantia de direitos na execução penal." (CACICEDO, Patrick. O controle judicial da execução penal no Brasil: ambiguidades e contradições de uma relação perversa. Revista Brasileira de Direito Processual Penal, Porto Alegre, vol. 4, n. 1, p. 413-432, jan./abr. 2018).

"As faltas médias e leves são tipificadas, no caso de São Paulo, pela SAP, órgão da execução penal que concentra competências administrativas relativas às 170 unidades prisionais do território paulista. A SAP prevê um extenso rol de 23 faltas médias (artigo 45) e 11 faltas leves (artigo 44)." (PINTO, Patrícia Bocardo Batista. Faltas disciplinares em penitenciárias femininas: um estudo das decisões do TJSP. Dissertação (Mestrado em Direito) - Fundação Getúlio Vargas - Escola de Direito de São Paulo, São Paulo, 2019, p. 54). 
a ordem ou a disciplina; fugir; possuir, indevidamente, instrumento capaz de ofender a integridade física de outrem; provocar acidente de trabalho; descumprir, no regime aberto, as condições impostas; inobservar os deveres previstos nos incisos II e V, do artigo 39, da mesma Lei (obediência ao servidor e respeito a qualquer pessoa com quem deva relacionar-se e execução do trabalho, das tarefas e das ordens recebidas); tiver em sua posse, utilizar ou fornecer aparelho telefônico, de rádio ou similar, que permita a comunicação com outros presos ou com o ambiente externo. Além disso, recentemente, a Lei no 13.964 de 2019 tipificou como falta disciplinar a recusa ao procedimento de identificação do perfil genético.

No art. 51 da mesma lei, estão previstas as faltas graves para os condenados à pena restritiva de direitos, quais sejam: descumprir, injustificadamente, a restrição imposta; retardar, injustificadamente, o cumprimento da obrigação imposta; e inobservar os deveres previstos nos incisos II e V, do artigo 39 - obediência ao servidor e respeito a qualquer pessoa com quem deva relacionar-se e execução do trabalho, das tarefas e das ordens recebidas.

Diante do reconhecimento judicial da prática do fato previamente definido em lei, o Juiz poderá impor consequências jurídicas aos sentenciados, que acabam por agravar significativamente, o modo de cumprimento de pena dos detentos envolvidos.

Conforme a pesquisa realizada, após o reconhecimento do ato indisciplinado considerado grave, o juiz, normalmente, determina o reinício da contagem do lapso para fins de progressão, a regressão de regime, se cabível, e a perda de até $1 / 3$ dos dias remidos.

Ada Pellegrini Grinover afirma que esses efeitos são considerados legítimos em razão da própria natureza da sentença penal condenatória, que contém a chamada cláusula rebus sic stantibus, que autoriza a modificação do modo de cumprimento da pena durante o processo executório, alterando-se de acordo com o surgimento de novos fatos no curso da execução ${ }^{21}$.

21 "A sentença penal contém a cláusula rebus sic stantibus, como sentença determinativa que é: o juiz fica, assim, autorizado, pela natureza mesma da sentença, a agir por equidade, operando a modificação objetiva da sentença sempre que haja mutação nas circunstâncias fáticas. Cumpre lembrar que a sentença determinativa transitada em julgado, sendo porém passível de um processo 
Diante de tantos malefícios, é obvio que a falta grave possui íntima ligação com a liberdade de locomoção dos sentenciados ${ }^{22}$. Por esse motivo, os procedimentos judiciais deveriam ser cuidadosos e individualizados, visando descobrir os verdadeiros motivos que deram ensejo ao ato faltoso, garantindo amplo acesso à justiça e ao juiz natural, dentre outros direitos previstos na Constituição Federal e na legislação infraconstitucional, evitando que o Poder Executivo interfira diretamente no tempo e modo de cumprimento da pena dos sentenciados.

Na prática isso não acontece ${ }^{23}$. Ao invés disso, as autoridades administrativas instauram centenas de procedimentos disciplinares todos

de integração em obediente a cláusula que contém; é, pois, suscetível de revisão, no processo de execução, nos casos expressamente autorizados por lei. É assim que se explica, processualmente, o fenômeno das modificações da sentença condenatória penal transitada em julgado, daí derivando a extensa gama de atividades jurisdicionais no processo de execução penal, em cujo curso as modificações se operam." (GRINOVER, Ada Pellegrini. Processo de execução e direito de defesa. Revista de informação legislativa, Brasília, v. 59, n. 15 , p. 56,1978$)$.

22 "Através da sindicância, o poder de determinar a qualidade e a duração efetiva do período de reclusão, os direitos adquiridos e os lapsos de progressão, escapa ao judiciário, que acaba por exercer um papel secundário, de mero avalista. O fluxo de processos de execução penal de um preso castigado em sindicância é totalmente alterado, em primeiro lugar, porque o período do pote não encerra o castigo; o preso volta para o raio, mas carrega um novo lapso a ser cumprido - um tempo de reabilitação, que pode chegar a um ano em casos de falta grave. Nesse período, nenhum peido de benefício poderá ser feito e o que já tramita ficará parado. Ainda, para aqueles que já estão em regime semiaberto, a sindicância pode levar à regressão cautelar. Finalmente, após o cumprimento do prazo de reabilitação (sem novas faltas), o registro de sindicância em seu prontuário passa a condicionar, negativamente, as decisões do juiz a respeito da concessão de benefícios que o preso venha a ter direito, mesmo depois de muitos anos. Tais impactos dos processos de sindicâncias no desenvolvimento das penas são fontes de muita angústia e ansiedade num raio de penitenciária, objetos de muitas dúvidas e questionamentos nas visitas pastorais." (GODOI, Rafael. Fluxos em cadeia: as prisões em São Paulo na vidada dos tempos. Tese (Doutorado em Sociologia) - Departamento de Sociologia, FFLCH, USP, São Paulo, 2015, p.99).

23 "Desde esse ponto de vista, é possível discutir a precariedade das estruturas voltadas à defesa jurídica gratuita; o desconhecimento, por parte de promotores e juízes, das condições reais de encarceramento; a inadequação dos recursos técnicos e administrativos das varas; a falta de qualificação dos profissionais - os déficits de formação, seja em técnicas de gestão, seja em 
os anos e, na grande maioria dos casos, tais procedimentos são marcados pela ausência de atos formais, pela inércia defensiva, entre outras irregularidades que violam o princípio do devido processo legal.

Esse ilegal comportamento, em razão do constante processo de desjudicialização das Varas de Execuções Penais ${ }^{24}$, normalmente é homologado pelo Judiciário, que acaba punindo em demasia vários sentenciados, utilizando-se para tanto de procedimentos de praxe, fazendo com que a maioria dos acusados sejam condenados sem direito efetivo de defesa, sem acesso ao juiz natural, como base exclusivamente nos elementos administrativos irregulares ${ }^{25}$.

\section{A METODOLOGIA E O RESULTADO DAS PESQUISAS}

Por se tratar de exame relacionado a matéria envolvendo Execução Penal, em que parte dos processos ainda são físicos no Estado de São Paulo, foi necessário limitar-se aos processos digitais. Assim, a pesquisa tem como objeto os procedimentos julgados pelo Departamento Estadual de Execução Criminal da $2^{\circ}$ RAJ (DEECRIM-2 ${ }^{\mathrm{a}} \mathrm{RAJ}$ ) submetidos ao Tribunal de Justiça de São Paulo, por meio de agravo em execução penal, com o

direitos humanos". (GODOI, Rafael. Fluxos em cadeia: as prisões em São Paulo na vidada dos tempos. Tese (Doutorado em Sociologia) - Departamento de Sociologia, FFLCH, USP, São Paulo, 2015, p.92).

24 "Infelizmente, psicólogos, psiquiatras, assistentes sociais, diretores de Unidades Prisional, Diretores de Escola, personagens que não estão inseridos no Poder Judiciário, mas sim no Poder Executivo, hoje decidem o destino dos presos". (MENEZES GULLA, Gabriela. Ideias para a construção de uma Execução Penal. In: democrática. ed. 1. Rio de Janeiro: NUSPEN, 2010, p. 125).

25 “Tem-se, assim, que a caracterização do processamento das faltas graves como de natureza administrativa tem implicações perversas para a pessoa sancionada, uma vez que o que está em jogo é, em última análise, a sua liberdade. Ainda assim, as sanções aplicáveis pela administração não são submetidas ao controle jurisdicional, e as sanções aplicáveis pelo judiciário são tratadas como meros "efeitos" do registro de falta grave, sem grandes consequências à vida da pessoa sancionada." (PINTO, Patrícia Bocardo Batista. Faltas disciplinares em penitenciárias femininas: um estudo das decisões do TJSP. Dissertação (Mestrado em Direito) - Fundação Getúlio Vargas, Escola de Direito de São Paulo, São Paulo, 2019, p. 68). 
objetivo de responder a seguinte pergunta: os procedimentos disciplinares analisados respeitam direitos e garantias fundamentais na prática?

Visando comprovar esse distanciamento entre o "direito dos livros e o direito na prática" ${ }^{26}$, a pesquisa prestou-se a: I) identificar acórdãos julgados pelo TJ/SP, originados de recursos de agravo em execução interpostos contra decisões do DEECRIM-UR2; II) analisar os documentos anexados aos recursos, a fim de conferir informações ligadas ao cumprimento de direitos e garantias nos procedimentos disciplinares (administrativos e judiciais); III) examinar as consequências imputadas aos detentos pelas decisões judiciais; IV) apontar a possibilidade das faltas disciplinares estarem interferindo na rotatividade dos presídios locais, com base em dados oficiais. Limitando-se, no entanto, a análise da existência (ou não) de determinadas formalidades ligadas a efetivação do devido processo legal, deixando de analisar questões ligadas ao conteúdo material dos procedimentos, as peculiaridades de cada falta disciplinar, assim como a existência ou não de recursos aos Tribunais Superiores.

Por meio de acesso ao portal eletrônico do mencionado Tribunal e da ferramenta "Consulta de Jurisprudência", foi possível realizar a seleção dos documentos analisados. Para tanto, foi necessário o uso de diversas palavras chaves visando limitar a matéria a ser pesquisada, para alcançar o maior número de decisões possíveis envolvendo o tema ${ }^{27}$.

26 "O descompasso entre o "direito nos livros" [law in the books] e o "direito na prática" [law in action] não seria imputável apenas à defasagem ou à "fase", mas principalmente daria expressão à descontinuidade entre cultura e estrutura social”. (GALANTER, Marc. Por que"quem tem" sai na frente: especulações sobre os limites da transformação no direito. Trad: CHASIN, Ana Carolina (Org.. São Paulo: FGV DIREITO SP, 2018).

27 Inicialmente, deve ser acessado o portal eletrônico do Tribunal de Justiça do Estado de São Paulo (www.esaj.tjsp.jus.br). Em seguida, deve-se clicar no link "Consulta de Jurisprudência”. Após, no tópico "Consulta Completa” e, depois, em "Pesquisa Livre". No campo "Palavras Chaves", de modo a alcançar o maior número de decisões possíveis, utilizou-se os seguintes dizeres: “deecrim ur2 agravo em execução falta grave”. Por fim, foi feita a seleção da comarca de Araçatuba/SP e os acórdãos publicados pelos órgãos colegiados entre 01/08/2019 até 20/12/2019. Após a seleção dos acórdãos, foi necessário consultar individualmente o número dos processos em segunda instância para ter acesso aos documentos anexados ao recurso ("consulta de processo em segundo grau"). 
Em seguida, foram estabelecidos alguns recortes, limitando a pesquisa à comarca de Araçatuba, sede do DEECRIM-UR2, e aos acórdãos publicados entre os períodos de 01 de agosto 2019 até 20 de dezembro de 2019 pelo TJ/SP. O recorte espacial teve como fundamento a crescente construção de presídios nos últimos anos na região de Araçatuba, interior do Estado de São Paulo. Já o recorte temporal, limitou-se ao segundo semestre de 2019, período em que se desenvolveram as atividades do "I Seminário de Desenvolvimento do Estado Democrático de Direito" da Faculdade de Direito de Ribeirão Preto (FDRP/USP), onde a pesquisa foi apresentada em sua fase inicial e recebeu importantes orientações para enfrentar os principais problemas metodológicos.

Além disso, é importante registrar que, por se tratar de ambiente eletrônico alimentado pelo corpo funcional do próprio Tribunal, é possível que mesmo com delineamento feito, a pesquisa não tenha alcançado todos os procedimentos julgados pelos juízes do DEECRIM- 2a RAJ, dentro dos recortes estabelecidos. No entanto, em razão do número de processos localizados, foi possível atingir os resultados esperados. Ao final, foram localizados 101 julgados.

Após a seleção dos acórdãos, foi necessário consultar individualmente o número dos processos em segunda instância, para ter acesso aos documentos anexados aos recursos (procedimento administrativo, manifestação das partes e decisão de primeira instância).

A coleta de dados foi feita e registrada por meio de planilha dívida em três partes. Na primeira, foram discriminados os dados que possibilitam a conferência das informações coletadas: "Número do Agravo em Execução"; "Assunto"; "Câmara Julgadora”; "Processo de Origem”; "Comarca de Origem"; "Unidade onde a falta foi praticada"; "Número de ordem do Procedimento"; "Nome do Sentenciado"; "Número de sentenciados envolvidos na falta"; "Data da Falta".

Feito o preenchimento dos campos iniciais, foram descartados os procedimentos que não se tratavam de recurso de Agravo de Execução, os que não se referiam ao julgamento de faltas disciplinares e, por fim, aqueles que não foram decididos pelos juízes do DEECRIM-2a RAJ. Após o referido descarte, que não foi capaz de comprometer os resultados da pesquisa, restaram então 56 procedimentos disciplinares que constituem o objeto principal do trabalho (Anexo I). 
Em que pese os procedimentos tenham sido julgados na localidade delimitada, verifica-se que as sindicâncias que deram origem as decisões judiciais foram instauradas em diversos estabelecimentos prisionais, localizados em 28 cidades do Estado de São Paulo ${ }^{28}$. Isso acontece, pois a competência para o julgamento é estabelecida de acordo com a localidade atual do sentenciado e não da penitenciaria onde o fato foi praticado.

Outro dado que nos chamou atenção foi o número de presos elencados nos comunicados de evento analisados, totalizando 536 sentenciados acusados de praticar ato indisciplinado, ou seja, uma média aproximada de 09 presos por comunicado de evento.

O total de presos envolvidos ganha maior importância quando analisamos o número de ordem dos comunicados de evento que deram origem aos procedimentos disciplinares. Isso porque, as Unidades Prisionais instauraram um número significativo de sindicâncias todos os anos. Por exemplo, a Penitenciária Luís Aparecido Fernandes de Lavínia, que até o mês de outubro do ano de 2018 instaurou 712 procedimentos disciplinares $^{29}$, ou seja, uma média aproximada de 70 comunicados por mês durante o ano de 2018.

Desta forma, em que pese não seja possível estabelecer o número exato de presos envolvidos e comunicados de eventos instaurados nas penitenciárias locais, em razão da limitação do acesso as informações necessárias, os dados comprovam que as sindicâncias vêm sendo instauradas rotineiramente dentro das Unidades Prisionais locais, além de envolver vários sentenciados.

Na segunda parte da planilha, foram identificadas questões relacionadas ao objeto central da pesquisa, que envolvem o acesso à justiça e o devido processo legal no julgamento de faltas disciplinares.

28 Nas cidades de Americana, Irapuru, Nova Independência, Rolândia, Valparaiso, Praia Grande, Lavínia, Presidente Prudente, Ribeirão Preto, Birigui, Avaré, Itatinga, São Paulo, Avanhandava, Dracena, Marilia, Piracicaba, Reginópolis, Mirandópolis, São Bernardo do Campo, Iperó, Itapetininga, São José do Rio Preto, Cerqueira Cesar, Presidente Bernardes, Pontal e Pracinha, todas situadas no Estado de São Paulo.

TJ/SP. Tribunal de Justiça do Estado de São Paulo. Agravo em Execução: 0003643-30.2019.8.26.0509. Rel. Toloza Neto. $3^{a}$ Câmara Criminal. Disponível em <https://esaj.tjsp.jus.br/cposg/open.do>. Acesso em 03 fev. 2020. 
Para tanto, foi estabelecido uma série de perguntas a serem respondidas de forma objetiva: "Qual a data da citação?”; "Qual da data em foi iniciada a produção de provas no procedimento administrativo?”; "A defesa produziu ou requereu a produção de provas durante o procedimento administrativo?"; "O Ministério Público individualizou a conduta do sentenciado ao se manifestar sobre o procedimento administrativo?”; "A Defesa e o Ministério Público produziram alguma prova em juízo?”; "O sentenciado foi ouvido judicialmente?".

Nesta etapa, verificou-se que 35 dos procedimentos analisados continham vícios insanáveis na citação ${ }^{30}$, ou seja, aproximadamente $62 \%$ dos casos analisados possuem irregularidades na "exigência fundamental ao exercício do contraditório" ${ }^{31}$.

Além disso, em todos os casos analisados, a Defesa sequer produziu provas em sede administrativa, ou seja, manteve-se inerte na construção do conjunto probatório, limitando-se apenas ao acompanhamento do interrogatório e a apresentação da defesa final. Destaca-se nesta fase, que a grande maioria dos acusados foram acompanhados por advogados da Fundação Prof. Dr. Manoel Pedro Pimentel (FUNAP), vinculada à Secretaria de Administração Penitenciaria, que presta assistência jurídica às pessoas presas no estado de São Paulo ${ }^{32}$.

${ }^{30}$ Foi considerado vício a ausência de citação, as citações realizadas após a oitiva da primeira testemunha, as citações sem assinatura, assim como as efetuadas no prazo inferior a três dias antes do início da oitiva das testemunhas e demais envolvidos, de acordo com Resolução 144 de 2010, da Secretaria da Administração Penitenciária do Estado de São Paulo.

31 GRINOVER, Ada Pellegrini; GOMES FILHO, Antonio Magalhães; FERNANDES, Antonio Scarance. As nulidades no processo penal. 11. ed. São Paulo: Revista dos Tribunais, 2009, p. 103.

32 "Embora esteja legalmente previsto que todo a sindicância deve seguir os princípios do contraditório e da ampla defesa, os advogados da FUNAP que trabalham na unidade pouco participam desse particular processo. Muitos presos relatam que prestaram depoimentos ou compareceram a oitivas sem a assistência de um advogado de defesa, e que tudo o que falaram, na verdade, não seve consequência prática alguma, bastando a acusação do ASP para imputar-lhes a culpa." (GODOI, Rafael. Fluxos em cadeia: as prisões em São Paulo na vidada dos tempos. Tese (Doutorado em Sociologia) - Departamento de Sociologia, FFLCH, USP, São Paulo, 2015, p.92). 
Se não bastassem tamanhas irregularidades no âmbito penitenciário, quando os procedimentos foram submetidos à esfera judicial, o Ministério Público em todos os casos, sem exceção, se manifestou de forma genérica, limitando-se apenas a afirmação de que o procedimento estava formal e materialmente em ordem, requerendo a imposição das consequências ao ato faltoso, sem sequer descrever o fato, aprofundar no conjunto probatório e descrevendo, com exatidão, a conduta do sentenciado.

Neste momento, verifica-se uma espécie de atuação como fiscal do procedimento, deixando de lados os ônus impostos pelo sistema acusatório, dificultando o trabalho da defesa e favorecendo arbitrariedades das autoridades administrativas.

Adiante, ainda na esfera judicial, verificou-se que em apenas 01 dos procedimentos analisados houve a produção de prova em juízo. Neste caso isolado, a Defesa juntou aos autos documentação visando comprovar que o sentenciado na época do fato era dependente químico. Nos outros 55 casos, nenhuma prova foi produzida em juízo.

Por fim, outro ponto que chama atenção é que, em que pese a Defesa tenha requerido a oitiva judicial dos acusados na grande maioria dos casos, em nenhum deles o sentenciado não foi ouvido judicialmente, ou seja, em todos os procedimentos analisados os sentenciados não tiveram acesso a autoridade judicial. Esse dado, também nos chama atenção, pois releva a impessoalidade dos julgamentos e a relativização do direito básico de acesso ao juiz natural.

Por fim, na terceira parte da planilha, foram relacionadas as consequências imputadas pelo Juiz de Primeiro Grau e o posicionamento do Tribunal de Justiça de São Paulo sobre o caso, através das seguintes perguntas: "Qual a consequência da decisão proferida pelo juiz de primeiro grau?”; "Qual a decisão do Tribunal de Justiça de São Paulo como órgão revisor?”.

Após analisar o teor das decisões proferidas pelos juízes do DEECRIM-2a RAJ, constatou-se que em apenas 01 dos casos analisados a falta disciplinar de grave foi desclassificada para falta média, nos outros 55 casos os sentenciados, mesmo diante ausência de produção de provas em juízo e das irregularidades contidas nos procedimentos administrativos, foram condenados pela prática infração considerados graves. 
Ressalta-se que em nenhum dos casos o juiz teve contato pessoal com o acusado, além disso, até mesmo nos casos em que sentenciado foi regredido de regime não houve a solicitação de oitiva judicial, em total desacordo com o artigo 118 da Lei de Execuções Penais.

Quanto às consequências jurídicas atribuídas ao ato faltoso, todas as decisões condenatórias determinaram o reinício do lapso para fins de progressão a partir da data da falta, a perda parcial dos dias remidos e, quando cabível, a regressão de regime. Neste ponto, houve variação apenas no tocante a perda de dias remidos, levando-se em consideração que em 23 dos casos analisados os juízes determinaram a perda de apenas $1 / 6$ dos dias, nos demais foi determinada a perda da fração máxima permitida em lei (1/3).

Por fim, analisando o teor dos acórdãos proferidos pelo Tribunal de Justiça do Estado de São Paulo, constata-se que 04 procedimentos foram anulados, 07 dos sentenciados foram absolvidos, 02 tiveram suas condutas desclassificadas e apenas um detento teve sua punibilidade extinta em razão ocorrência do fenômeno da prescrição, ou seja, apenas 14 decisões foram reformadas.

Conclui-se, a partir das informações acima, que as decisões proferidas pelos juízes de primeiro grau possuem guarda no Tribunal de Justiça do Estado de São Paulo, o que nos remete a um possível caráter estadual da pesquisa.

Em síntese, as condenações administrativas, na grande maioria dos casos, são simplesmente confirmadas pelas pelo Poder Judiciário, não havendo como sustentar a natureza jurisdicional dos procedimentos disciplinares analisados. Na verdade, os agentes penitenciários são os verdadeiros responsáveis pelo julgamento dos presos e seus depoimentos são absolutos dentro do quadro probatório.

Neste cenário, o preso que atrasa alguns minutos para retornar do benefício de saída temporária recebe a mesma punição daquele que abandona o regime semiaberto; os que se revoltam com a falta de atendimento médico são punidos de forma idêntica aqueles que portam um aparelho telefônico dentro da cela. 
Por fim, analisando o relatório emitido em junho de 2017, pelo Departamento Penitenciário Nacional ${ }^{33}$, nota-se que na época aproximadamente $76 \%$ da população carcerária que cumpria pena nos estabelecimentos prisionais no Estado de São Paulo, encontrava-se em regime fechado, sendo esse número quatro vezes superior aos que cumpriam pena em regime semiaberto, mesmo a maior parte da população carcerária paulista tendo pena igual ou inferior a oito anos de prisão.

Outro dado que nos chama atenção é que o número de entrada é superiormente maior do que o número de saída de pessoas do sistema penitenciário paulista.

Assim, quando levamos em consideração os números apresentados e os requisitos objetivos legais necessários para progressão de regime, fica evidente que as condenações pela prática de faltas disciplinares de natureza grave contribuem como o problema da rotatividade dos presídios paulistas.

Ao final, verifica-se, na verdade, uma marcante contradição entre as garantias processuais expressamente previstas em lei e amplamente defendida pela doutrina, como apontado nos tópicos anteriores, com a realidade prática durante a execução da pena.

É como se o processo executório não tivesse tanta importância quanto os processos de conhecimento, como se os direitos dos sentenciados inerentes ao devido processo legal tivessem sidos afastados em virtude do trânsito em julgado da sentença penal condenatória, fazendo com que às lições mais valiosas da academia e o próprio texto da lei fossem extintos em decorrência da praxe processual.

No entanto, quando o assunto envolve faltas disciplinares, atos irregulares como esses são altamente lesivos ao sistema penitenciário local, seja em razão do sentimento de revolta e indignação da população carcerária, seja em decorrência da interferência na rotatividade dos presídios locais. Isso porque, sem direito de defesa, sem respeito ao devido processo legal, o número de condenações e arbitrariedade aumentam e em decorrência das consequências legais dadas ao ato indisciplinado - a

33 Disponível em < http://depen.gov.br/DEPEN/depen/sisdepen/infopen/ relatorios-sinteticos/infopen-jun-2017-rev-12072019-0721.pdf>. Acesso em 03 fev. 2020. 
rotatividade do sistema diminui, fazendo com que muitos reclusos cumpram maior parte de sua pena em regime fechado em razão de injustiças legitimadas pela prática forense.

Quanto a rotatividade, é importante destacar que esse fato gera, por sua vez, uma espécie de "efeito cascata”, que torna-se imensurável a longo e médio prazo, vez que quanto mais homens amontoados em regime fechado em condições sub-humanas, maior o número de atos indisciplinados praticados em decorrência desse ambiente hostilizado, ou seja, maior o número de sindicâncias instauradas, maior o números de condenações de praxe.

\section{CONSIDERAÇÕES FINAIS}

Em sede de conclusão, ressalta-se que vários fatores contribuem com a superlotação do sistema penitenciário do Estado de São Paulo, entre eles as faltas disciplinares, o objeto de análise da pesquisa, que assumi parcela significativa do problema no cenário atual.

Acontece que, pensar no fim do sistema punitivo durante a execução da pena é algo utópico e imaturo, vez que ainda não há alternativas legítimas para manutenção da ordem sem o sistema disciplinar pregado pela Lei de Execuções Penais. No entanto, é indispensável a concessão de garantias processuais aos acusados, assim como acesso integral à justiça por meio de interrogatório judicial, dentre outras medidas devem ser tomadas para garantir o efetivo direito de defesa, a fim de diminuir os efeitos maléficos das infrações disciplinares.

Outro ponto, relaciona-se com os problemas estruturais, humanos, advindo da falta de funcionários diante do alto número de sentenciados no sistema, mas só isso não basta. Para que a mudança aconteça, além da reforma estrutural, é necessária uma mudança de comportamento dos atores judiciais que atuam durante a fase executória da pena, que ainda continuam fascinados com teoria do delito, dando pouco valor a execução penal, esquecendo-se, no entanto, que fase executória é responsável pela legitimação do sistema de justiça criminal ${ }^{34}$.

34 "Os juristas-penalistas, preocupados primordialmente com a teoria do delito, sempre se descuraram da execução da sentença penal, com se a atividade jurídica se encesse com a condenação. A pena, mesma, foi relegada a um 
Adiante, ressalta-se a importância da pesquisa empírica nesse processo, principalmente no âmbito das Varas de Execuções Penais, com o objetivo de identificar e propor soluções centrais a esse distanciamento, servindo como instrumento de auxílio aos operadores das normas no plano prático, para que possam enfrentar com precisão os principais problemas.

Nota-se que esse abismo entre a vigência e a efetividade dos direitos e garantias fundamentais, marcado, evidentemente, pelo afastamento do Poder Judiciário Paulista da população carcerária, além contribuir com a superlotação dos presídios locais, também gera revolta na população carcerária, fazendo com que muitos detentos desistam da finalidade ressocializadora da pena e passem a enxergar o Estado como seu principal inimigo e o crime como solução.

Em meio as limitações, caso não seja possível a concessão das garantias processuais, deve-se, por meio de alteração legislativa e jurisprudencial, extinguir ou substituir determinadas consequências jurídicas atribuídas aos atos indisciplinados. Tais punições deveriam reservar-se-á apenas ao campo administrativo, de modo proporcional e, de preferência pedagógico, ainda recaindo sobre direitos dos reclusos, como o direito de visita, regalias, convívio com os demais detentos, entre outros, mas sempre de forma equilibrada, não interferindo na estrutura do sistema carcerário e no tempo de cumprimento de pena em regime fechado.

Por fim, conclui-se que é necessária a reforma do sistema disciplinar, em caráter de urgência, visando retomar a legitimidade da Execução Penal, através da concessão de garantias processuais ou da reformulação das consequências advindas do ato faltoso, retomando aos poucos a rotatividade dos presídios, contribuindo com o desencarceramento e, consequentemente, com o fortalecimento do Estado Democrático de Direito.

\section{REFERÊNCIAS}

AMARAL, Claudio do Prado. Em busca do devido processo de execução penal. Revista Brasileira de Ciências Criminais, São Paulo, n. 81, ano 17, 2007.

segundo plano. (CINTRA JÚNIOR, Dyrceu Aguiar Dias. A jurisdicionalização do processo de execução penal: o contraditório e a ampla defesa. Revista Brasileira de Ciências Criminais, n. 9, v. 3, p 115-116, 1995). 
CAVAlVANTE, Eduardo M. O Ministério Público na Execução Penal.. In: CARVALHO, Salo de (Org.). Crítica à Execução Penal. $2^{\circ}$ ed. Rio de Janeiro: Lumen. Juris, 2007.

CACICEDO, Patrick. O controle judicial da execução penal no Brasil: ambiguidades e contradições de uma relação perversa. Revista Brasileira de Direito Processual Penal, Porto Alegre, vol. 4, n. 1, p. 413-432, jan./abr. 2018. https://doi. org/10.22197/rbdpp.v4i1.111

CINTRA JÚNIOR, Dyrceu Aguiar Dias. A jurisdicionalização do processo de execução penal: o contraditório e a ampla defesa. Revista Brasileira de Ciências Criminais, n. 9, v. 3, p 115-116, 1995

FILHO, Luiz Carlos Gonçalves. A lei de execução penal e os efeitos decorrentes da prática de falta disciplinar de natureza grave. Dissertação (Mestrado em Direito) Pontifícia Universidade Católica de São Paulo, São Paulo, 2006.

GALANTER, Marc. Por que "quem tem" sai na frente: especulações sobre os limites da transformação no direito.Trad: CHASIN, Ana Carolina. São Paulo: FGV DIREITO SP, 2018.

GODOI, Rafael. Fluxos em cadeia: as prisões em São Paulo na vidada dos tempos. Tese (Doutorado em Sociologia) - Departamento de Sociologia, FFLCH, USP, São Paulo, 2015.

GRINOVER, Ada Pellegrini (1978). Processo de execução e direito de defesa. Revista de informação legislativa, Brasília, v. 59, n. 15, 1978.

GRINOVER, Ada Pellegrini; GOMES FILHO, Antonio Magalhães; FERNANDES, Antonio Scarance. As nulidades no processo penal. 11. ed. São Paulo: Revista dos Tribunais, 2009.

LOPES JR, Aury. Revisando o Processo de Execução Penal a partir da Instrumentalidade Garantista. In: CARVALHO, Salo de (Org.). Crítica à Execução Penal. $2^{\circ}$ ed. Rio de Janeiro: Lumen. Juris, 2007.

MACHADO, Maira Rocha; PINTO, Patrícia Bocardo Batista. A punição na punição na punição: as múltiplas sanções aplicadas em caso de falta grave nas decisões do TJSP. Revista Brasileira de Ciências Criminais. vol. 152, n. 27. p. 117-143, fev, 2019.

MENEZES GULLA, Gabriela. Ideias para a construção de uma Execução Penal. In: democrática. ed. 1. Rio de Janeiro: NUSPEN, 2010.

PAVARINI, Massimo; GIAMBERARDINO, André. Teoria da pena e execução penal. Uma introdução crítica. Rio de Janeiro: Lumem Juris, 2011.

PINTO, Patírcia Bocardo Batista. Faltas disciplinares em penitenciárias femininas: um estudo das decisões do TJSP. Dissertação (Mestrado em Direito) - Fundação Getúlio Vargas - Escola de Direito de São Paulo, São Paulo, 2019. 
PRADO, Geraldo. A execução Penal e o Sistema Acusatório. In: CARVALHO, Salo de (Org.). Crítica à Execução Penal. $2^{\circ}$ ed. Rio de Janeiro: Lumen. Juris, 2007. ROIG, Rodrigo Duque Estrada. Execução Penal: teoria crítica. 2 ed. São Paulo: Saraiva, 2016.

SCHIMIDT, Andrei Zenkner. Direitos, Deveres e Disciplina na Execução Penal. In: CARVALHO, Salo de (Org.). Crítica à Execução Penal. $2^{\circ}$ ed. Rio de Janeiro: Lumen. Juris, 2007.

\section{ANEXO I}

\begin{tabular}{|c|c|c|}
\hline $\begin{array}{l}\text { Número Agravo em } \\
\text { Execução no TJ/SP }\end{array}$ & $\begin{array}{l}\text { Câmara } \\
\text { julgadora }\end{array}$ & $\begin{array}{c}\text { Número do Processo } \\
\text { de Origem }\end{array}$ \\
\hline 0004158-65.2019.8.26.0509 & $14^{\mathrm{a}}$ & 0006766-64.2018.8.26.0996 \\
\hline 0002486-22.2019.8.26.0509 & $14^{\mathrm{a}}$ & 0009293-86.2018.8.26.0996 \\
\hline 0004965-85.2019.8.26.0509 & $15^{\mathrm{a}}$ & 0013961-03.2018.8.26.0996 \\
\hline 0004945-94.2019.8.26.0509 & $2^{\mathrm{a}}$ & 0001640-67.2017.8.26.0996 \\
\hline 0004954-56.2019.8.26.0509 & $13^{\mathrm{a}}$ & 0006056-84.2017.8.26.0509 \\
\hline 0005244-71.2019.8.26.0509 & $3^{\mathrm{a}}$ & 0002296-93.2018.8.26.0509 \\
\hline 0005119-06.2019.8.26.0509 & $5^{\mathrm{a}}$ & $7001965-27.2013 .8 .26 .0554$ \\
\hline 0005376-31.2019.8.26.0509 & $5^{a}$ & 0000865.29 .2015 .8 .26 .0509 \\
\hline 0003874-57.2019.8.26.0509 & $16^{\mathrm{a}}$ & 0001818-22.2017.8.26.0509 \\
\hline 0004738-95.2019.8.26.0509 & $15^{\mathrm{a}}$ & 0002751-97.2018.8.26.0496 \\
\hline 0004402-91.2019.8.26.0509 & $8^{\mathrm{a}}$ & 0006091-38.2017.8.26.0996 \\
\hline 0003538-53.2019.8.26.0509 & $12^{\mathrm{a}}$ & 0001383-65.2015.8.26.0041 \\
\hline 0003124-55.2019.8.26.0509 & $6^{\mathrm{a}}$ & 0001307-34.2015.8.26.0496 \\
\hline 0001753-56.2019.8.26.0509 & $8^{a}$ & 0014754-62.2016.8.26.0041 \\
\hline 0004692-09.2019.8.26.0509 & $5^{\mathrm{a}}$ & 0005493-39.2017.8.26.0041 \\
\hline 0003297-79.2019.8.26.0509 & $16^{\mathrm{a}}$ & 0002287-32.2018.8.26.0154 \\
\hline 0003285-65.2019.8.26.0509 & $16^{\mathrm{a}}$ & 0002342-87.2015.8.26.0509 \\
\hline
\end{tabular}




\begin{tabular}{|c|c|c|}
\hline $\begin{array}{l}\text { Número Agravo em } \\
\text { Execução no TJ/SP }\end{array}$ & $\begin{array}{l}\text { Câmara } \\
\text { julgadora }\end{array}$ & $\begin{array}{c}\text { Número do Processo } \\
\text { de Origem }\end{array}$ \\
\hline 0003634-68.2019.8.26.0509 & $16^{\mathrm{a}}$ & 0002101-74.2019.8.26.0509 \\
\hline 0003524-69.2019.8.26.0509 & $5^{\mathrm{a}}$ & $7000020-79.2014 .8 .26 .0615$ \\
\hline 0002683-74.2019.8.26.0509 & $5^{\mathrm{a}}$ & 0010517-14.2018.8.26.0041 \\
\hline 0003114-11.2019.8.26.0509 & $5^{\mathrm{a}}$ & 0004356-37.2017.8.26.0521 \\
\hline 0002957-38.2019.8.26.0509 & $4^{\mathrm{a}}$ & 0024198-22.2016.8.26.0041 \\
\hline 0003641-60.2019.8.26.0509 & $3^{\mathrm{a}}$ & 0001430-51.2019.8.26.0509 \\
\hline 0004076-34.2019.8.26.0509 & $7^{\mathrm{a}}$ & 0006115-02.2018.8.26.0521 \\
\hline 0003443-23.2019.8.26.0509 & $13^{\mathrm{a}}$ & $0021570-60.2016 .8 .26 .0041$ \\
\hline 0003748-07.2019.8.26.0509 & $13^{\mathrm{a}}$ & 0005848-66.2018.8.26.0509 \\
\hline 0000968-94.2019.8.26.0509 & $12^{\mathrm{a}}$ & 0002176-84.2017.8.26.0509 \\
\hline 0003440-68.2019.8.26.0509 & $11^{\mathrm{a}}$ & 0005771-91.2017.8.26.0509 \\
\hline 0002956-53.2019.8.26.0509 & $4^{\mathrm{a}}$ & 0002768-31.2017.8.26.0509 \\
\hline 0003643-30.2019.8.26.0509 & $3^{\mathrm{a}}$ & 0005345-45.2018.8.26.0509 \\
\hline 0001023-45.2019.8.26.0509 & $3^{\mathrm{a}}$ & 0006098-36.2017.8.26.0509 \\
\hline 0002280-08.2019.8.26.0509 & $3^{\mathrm{a}}$ & 0002280-08.2019.8.26.0509 \\
\hline 0002950-46.2019.8.26.0509 & $13^{\mathrm{a}}$ & 0009653-55.2017.8.26.0996 \\
\hline 0005952-58.2018.8.26.0509 & $12^{\mathrm{a}}$ & 0002838-82.2016.8.26.0509 \\
\hline 0005444-15.2018.8.26.0509 & $12^{\mathrm{a}}$ & $0002035-72.2016 .8 .26 .0615$ \\
\hline 0000874-49.2019.8.26.0509 & $9^{a}$ & 7000398-39.2014.8.26.0161 \\
\hline 0002387-52.2019.8.26.0509 & $4^{\mathrm{a}}$ & 0004549-54.2018.8.26.0509 \\
\hline 0001090-10.2019.8.26.0509 & $4^{\mathrm{a}}$ & 0017366-70.2016.8.26.0041 \\
\hline 0002834-40.2019.8.26.0509 & $4^{\mathrm{a}}$ & 0006220-83.2016.8.26.0509 \\
\hline 0002949-61.2019.8.26.0509 & $4^{\mathrm{a}}$ & 0007260-60.2017.8.26.0026 \\
\hline 0001761-33.2019.8.26.0509 & $11^{\mathrm{a}}$ & 0003263-41.2018.8.26.0509 \\
\hline 0006395-09.2018.8.26.0509 & $12^{\mathrm{a}}$ & 0021723-93.2016.8.26.0041 \\
\hline
\end{tabular}




\begin{tabular}{|c|c|c|}
\hline $\begin{array}{c}\text { Número Agravo em } \\
\text { Execução no TJ/SP }\end{array}$ & $\begin{array}{c}\text { Câmara } \\
\text { julgadora }\end{array}$ & $\begin{array}{c}\text { Número do Processo } \\
\text { de Origem }\end{array}$ \\
\hline $0002839-62.2019 .8 .26 .0509$ & $12^{\mathrm{a}}$ & $0003326-64.2017 .8 .26 .0521$ \\
\hline $0001934-57.2019 .8 .26 .0509$ & $13^{\mathrm{a}}$ & $0005161-09.2016 .8 .26 .0041$ \\
\hline $0002285-30.2019 .8 .26 .0509$ & $4^{\mathrm{a}}$ & $0007148-57.2018 .8 .26 .0026$ \\
\hline $0001764-85.2019 .8 .26 .0509$ & $4^{\mathrm{a}}$ & $0017366-70.2016 .8 .26 .0041$ \\
\hline $0001315-30.2019 .8 .26 .0509$ & $4^{\mathrm{a}}$ & $0002825-20.2015 .8 .26 .0509$ \\
\hline $0001008-76.2019 .8 .26 .0509$ & $13^{\mathrm{a}}$ & $0000155-43.2018 .8 .26 .0496$ \\
\hline $0000881-41.2019 .8 .26 .0509$ & $4^{\mathrm{a}}$ & $0005246-75.2018 .8 .26 .0509$ \\
\hline $0001191-47.2019 .8 .26 .0509$ & $9^{\mathrm{a}}$ & $0001632-60.2018 .8 .26 .0154$ \\
\hline $0001359-49.2019 .8 .26 .0509$ & $9^{\mathrm{a}}$ & $0009045-23.2018 .8 .26 .0996$ \\
\hline $0001497-16.2019 .8 .26 .0509$ & $16^{\mathrm{a}}$ & $0000727-23.2019 .8 .26 .0509$ \\
\hline $0001786-46.2019 .8 .26 .0509$ & $6^{\mathrm{a}}$ & $0014188-54.2017 .8 .26 .0502$ \\
\hline $0000554-96.2019 .8 .26 .0509$ & $6^{\mathrm{a}}$ & $0005912-70.2018 .8 .26 .0026$ \\
\hline $0001316-15.2019 .8 .26 .0509$ & $8^{\mathrm{a}}$ & $0019080-31.2017 .8 .26 .0041$ \\
\hline $0001081-48.2019 .8 .26 .0509$ & $12^{\mathrm{a}}$ & $0005726-53.2018 .8 .26 .0509$ \\
\hline
\end{tabular}




\section{Informações adicionais e declarações dos autores (integridade científica)}

Agradecimentos (acknowledgement): Agradeço aos professores pelas precisas orientações e indicações bibliográficas que contribuíram para concretização do trabalho e para o ajuste das principais questões metodológicas.

Declaração de conflito de interesses (conflict of interest declaration): o autor confirma que não há conflitos de interesse na realização das pesquisas expostas e na redação deste artigo.

Declaração de autoria e especificação das contribuições (declaration of authorship): todas e somente as pessoas que atendem os requisitos de autoria deste artigo estão listadas como autores; todos os coautores se responsabilizam integralmente por este trabalho em sua totalidade.

Declaração de ineditismo e originalidade (declaration of originality): o autor assegura que o texto aqui publicado não foi divulgado anteriormente em outro meio e que futura republicação somente se realizará com a indicação expressa da referência desta publicação original; também atesta que não há plágio de terceiros ou autoplágio.

Dados do processo editorial

(http://www.ibraspp.com.br/revista/index.php/RBDPP/about/editorialPolicies)

- Recebido em: 03/04/2020

- Controle preliminar e verificação de plágio: 03/04/2020

- Avaliação 1: 22/04/2020

- Avaliação 2: 23/04/2020

- Avaliação 3: 23/04/2020

- Decisão editorial preliminar: 12/06/2020

- Ressubmissão: 24/02/2021

- Decisão editorial final: 19/06/2021

\section{Equipe editorial envolvida}

- Editor-chefe: 1 (VGV)

- Editor-assistente: 1 (RDG)

- Revisores: 3 


\section{COMO CITAR ESTE ARTIGO:}

MENDES, Bruno Barros. Falta grave e sua interferência na rotatividade dos presídios do Estado de São Paulo: uma análise a partir das decisões do DEECRIM - $2^{\mathrm{a}} \mathrm{RAJ}$. Revista Brasileira de Direito Processual Penal, Porto Alegre, vol. 6, n. 3, p. 2311-2338, set./dez. 2020. https://doi.org/10.22197/rbdpp.v6i3.361 